\title{
La pertinencia actual de aspectos premodernos a consecuencia de las carencias de la modernidad
}

\section{Actual reappraisal of premodern aspects resulting from the delusions of modernity}

\author{
HUGO C. F. MANSILLA \\ Academia de Ciencias de Bolivia (Bolivia)
}

Recibido: 24-4-2012

Aprobado definitivamente: 24-5-2012

\section{RESUMEN}

La eliminación de instituciones y concepciones premodernas es considerada generalmente como imprescindible y positiva para acelerar la evolución histórica y alcanzar el anhelado objetivo del progreso material. La tradicionalidad ha sido desde entonces vista como algo fundamentalmente negativo. El proceso de modernización engloba, sin embargo, factores destructivos, que recién ahora empiezan a ser percibidos de forma realista. Algunos elementos premodernos merecen una mejor suerte en la consciencia intelectual, como la religión en cuanto fuente de sentido y consuelo. Aun es posible rescatar las tradiciones razonables, y combinarlas con lo positivo de la modernidad. Esfuerzos sincretistas similares en otros campos constituyen gran parte de la historia universal.

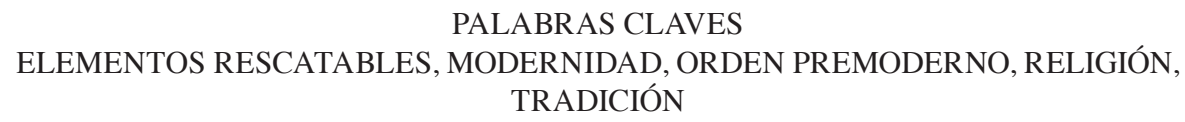




\begin{abstract}
The elimination of premodern institutions and values has been generally considered as unavoidable and therefore as positive for the purposes of accelerating the historical evolution of any society. The traditional order has been supposed to be something basically negative. Modernization embraces, however, destructive factors, which now are increasingly perceived in a more realistic manner. Some premodern aspects deserve a better destiny in collective conscience. An example of that is religion as a source of sense and comfort. It is still possible to rescue some factors of premodern societies and to blend them with the positive aspects of modernity. Similar syncretizing efforts in other fields constitute a fair portion of the history of mankind.
\end{abstract}

KEYWORDS

MODERNITY, PREMODERN SOCIETY, PRESERVABLE ASPECTS, RELIGION, TRADITION

\title{
I. LAS DESILUSIONES DEL MUNDO CONTEMPORÁNEO
}

LA ELIMINACIÓN DE INSTITUCIONES, normas y concepciones premodernas fue considerada por marxistas y liberales como imprescindible y, por ende, como altamente positiva y promisoria para acelerar la evolución histórica de todas las sociedades y alcanzar aceleradamente el anhelado objetivo del progreso material. La tradicionalidad, en cuanto noción global opuesta a la modernidad, ha sido vista desde entonces como algo fundamentalmente negativo o, dicho de modo más benevolente, como algo anacrónico y digno de desaparecer lo más pronto posible. El proceso de modernización, celebrado por los padres del marxismo y los apologistas del capitalismo, engloba, sin embargo, factores destructivos, que recién ahora empiezan a ser percibidos en toda su magnitud e intensidad. Numerosos aspectos de la tradicionalidad, por el mero hecho de pertenecer al mundo premoderno y pre-industrial (es decir a priori de un análisis de cada caso), no pueden ser calificados de retrógrados, perniciosos e inhumanos, sobre todo teniendo en cuenta la profunda desilusión que ha causado la modernidad en numerosos campos de la actividad humana.

Pese a la impopularidad del designio de rescatar algunas tradiciones premodernas, este ensayo pretende salvar del olvido ciertos elementos premodernos que merecen una mejor suerte en la consciencia intelectual y en el imaginario social. Tradición proviene de tradere, que tiene los significados de transmitir, legar algo de un pariente a otro, o arrastrar normas de una generación a la siguiente. Originalmente tenía una connotación de inmediatez, cercanía corporal y ámbito familiar: lo que pasaba de una persona a otra. La tradición -y particularmente la tradicionalidad en cuanto sistema social previo al racionalismo instrumental de índole universalista- ha conocido escasos procedimientos anónimos, im- 
personales y abstractos. Su motor no era la consciencia reflexiva de sí misma, sino la normatividad no cuestionada, derivada de formas elementales y hasta atávicas de organización social y de los llamados vínculos primarios. El mundo burgués-capitalista y el intercambio de equivalentes expresable en dinero asestaron el golpe más duro a las tradiciones, lo que naturalmente no significa que la evolución moderna sea históricamente ineludible y exclusivamente positiva. De todas maneras es inhumano menospreciar la tradición porque esto conlleva ignorar el sufrimiento acumulado, el dolor de nuestros propios antepasados, la angustia de las generaciones que nos precedieron, y desdeñar las palabras, los aromas y los colores de nuestra infancia y de nuestro origen. Es despreciar lo que nos brinda un sentimiento de pertenencia e identidad inconfundibles, lo que fundamenta la confianza, aquello que también está entretejido con la esperanza y la nostalgia, y a menudo también con el desconsuelo. No hay que subestimar la tradición, sino hay que confrontarla con las formas más avanzadas de la consciencia crítica y tratar de vislumbrar lo aceptable que pudiera haber en ella. Debemos considerar la tesis, tal vez demasiado optimista, de HansGeorg Gadamer, quien sostuvo que la tradición no se basa necesariamente en la defensa de lo convencional, sino en la continua acción de dar forma a la vida social-ética, es decir en hacer consciente la realidad, lo que conduciría a una nueva dimensión de libertad. ${ }^{1}$

Max Horkheimer señaló que una de las tareas primordiales de la teoría crítica en la actualidad era discernir lo que había que preservar del pasado -sobre todo normativas y logros culturales- y lo que era necesario combatir del presente. ${ }^{2}$ Cada progreso conlleva la eliminación de algo que ha sido positivo: es conveniente tener consciencia y dejar constancia de ello. El dolor y el duelo por estas pérdidas sirven para relativizar el progreso material, no siempre tan razonable: lo irracional sería aceptar todo progreso por el mero hecho de serlo. Una forma aceptable de ser conservador hoy en día es ser partidario de preservar los ecosistemas amenazados por el progreso humano y lo razonable de la tradición. La conservación de los grandes legados culturales del pasado y de lo que queda de naturaleza en este mundo se transforma entonces en una acción progresista.

En el mundo contemporáneo, tan alejado de la tradicionalidad, las exhaustivas incursiones de la razón meramente instrumental en la praxis cotidiana del

1 Hans-Georg Gadamer, Wahrheit und Methode. Grundzïge einer philosophischen Hermeneutik (Verdad y método. Bases de una hermenéutica filosófica), Tübingen: Mohr-Siebeck 1975,p. 533 sq. Cf. también Theodor W. Adorno, Thesen über Tradition (Tesis sobre la tradición), en: Adorno, Ohne Leitbild. Parva Aesthetica (Sin paradigma), Frankfurt: Suhrkamp 1967, pp. 29, 35.

2 Max Horkheimer, Kritische Theorie gestern und heute (La teoría crítica ayer y hoy), en: Horkheimer, Gesellschaft im Übergang (Sociedad en transición), Frankfurt: Athenäum-Fischer 1972, p. 166. 
hombre y la expansión de mecanismos burocráticos en las relaciones sociales («la colonización del mundo de la vida por los sistemas técnicos») ${ }^{3}$ han conllevado el empobrecimiento de las estructuras de comunicación interhumanas y el aumento de los fenómenos clásicos de alienación hasta alturas insospechadas para los clásicos del pensamiento social. Y esta patología social puede ser analizada adecuadamente si se toman en consideración puntos de vista comparativos, por ejemplo los que brinda la confrontación con los elementos positivos que también ha poseído el orden premoderno y preburgués.

Los progresos de las ciencias modernas, los triunfos de la tecnología y hasta los adelantos de la filosofía, las artes y la literatura han producido un mundo donde el hombre experimenta un desamparo existencial, profundo e inescapable que no advirtió en las comunidades premodernas que le brindaban, a pesar de todos sus innumerables inconvenientes, la solidaridad inmediata de la familia extendida y del círculo de allegados, un sentimiento generalizado de pertenencia a un hogar y una experiencia de consuelo y comprensión, es decir: algo que daba sentido a su vida. ${ }^{4}$ Desde el siglo XX esta situación tiende a agravarse a causa de un sistema civilizatorio centrado en el crecimiento y el desarrollo materiales a ultranza, sistema que, por un lado, fomenta la soledad del individuo en medio de una actividad frenética y, por otro, diluye las diferencias entre lo privado y lo público, entre el saber objetivo y la convicción pasajera, entre el arte genuino y la impostura de moda, entre al amor verdadero y el libertinaje hedonista. No es de extrañar que dilatados fenómenos de anomia desintegradora surjan cada vez más frecuentemente en estas sociedades de desenvolvimiento tecnológico impecable y dilatada pobreza espiritual.

Sería necio negar los logros y las ventajas que entre tanto ha alcanzado la civilización de Occidente mediante su combinación de economía de libre mercado y democracia representativa pluralista. La tolerancia ideológica y el bienestar general pertenecen a esta constelación, única en la historia por su

3 Jürgen Habermas, Theorie des kommunikativen Handelns (Teoría de la actuación comunicativa), Frankfurt: Suhrkamp 1981, vol. I, p. 107 sq.; vol. II, p. 171 sqq., 229 sqq.; sobre esta temática cf. Willem van Reijen, Die Aushöhlung der abendländischen Kultur. Jürgen Habermas' magnum opus (La socavación de la cultura occidental. La obra magna de Jürgen Habermas), en: Detlef Horster, Habermas zur Einfuihrung (Introducción a Habermas), Hamburgo: Junius 1990, pp. 75-81.

4 Cf. la hermosa y breve obra de Karl Löwith, Wissen, Glaube und Skepsis (Saber, creer y escepticismo), Göttingen: Vandenhoeck \& Ruprecht 1962, p. 76 sq.: Ya a partir del siglo XVII se expande en Europa Occidental la convicción de que el mundo pierde su acostumbrada coherencia, descomponiéndose en fragmentos ininteligibles, y no se encuentra una brújula adecuada para subsanar este dilema. Cf. también Karl Löwith, El hombre en el centro de la historia. Balance filosófico del siglo XX, Barcelona: Herder 1997, passim.- Sobre la vida y obra de Löwith cf. Wiebrecht Ries, Karl Löwith, Stuttgart: Metzler 1992; y la celebrada biografía intelectual: Enrico Donaggio, Una sobria inquietud. Karl Löwith y la filosofía, Buenos Aires: Katz 2006. 
magnitud e intensidad. Pero la obligación del espíritu crítico es percatarse de los aspectos negativos inherentes a todo ordenamiento social. Al lado de la prosperidad de Occidente puede detectarse -en las palabras de Octavio Paz-el nihilismo de la abdicación: no hay «ni una sabiduría más alta ni una cultura más profunda». «El panorama espiritual de Occidente es desolador: chabacanería, frivolidad, renacimiento de las supersticiones, degradación del erotismo, el placer al servicio del comercio y la libertad convertida en la alcahueta de los medios de comunicación». ${ }^{5}$

La pérdida de la diversidad y el colorido socio-culturales y su correlato, la homogeneización del planeta entero según los cánones de la cultura del consumismo masivo y del principio de rendimiento, constituyen un programa innegablemente popular (el progreso!), pero generan al mismo tiempo una atmósfera general de melancolía: la inmensa mayoría de los habitantes de estas sociedades técnicamente exitosas sabe que nunca alcanzará el nivel de consumo que la televisión le insinúa como normativo. La propaganda, por ejemplo, estimula a todos los consumidores a vestirse de la misma manera y les sugiere al mismo tiempo que así llegarán a ser originales y hasta únicos. Ellos no disponen ya de referentes que les puedan brindar una identidad e individualidad específicas y, por otro lado, están obligados a exhibir una alegría y un optimismo artificiales según los dictados de los medios masivos de comunicación. «La civilización industrial -dice Iring Fetscher- satisface promesas materiales y despierta esperanzas insaciables». ${ }^{6}$ De acuerdo a Konrad Lorenz el mundo contemporáneo exige comportamientos altamente diferenciados, que se complementan paradójicamente con una «atrofia de la inactividad» y una «ceguera creciente ante los valores»: nuestros potenciales éticos y estéticos decaen en un orden social hiperdesarrollado que ya no permite al hombre tener un sentimiento tan anacrónico como la admiración ante la belleza de la naturaleza o el respeto de los méritos individuales de sus congéneres. ${ }^{7}$ El falso igualitarismo -la ideología que menosprecia las diferencias y jerarquías basadas en el talento y el mérito-que predican muchas corrientes contemporáneas (incluyendo tendencias postmoder-

5 Octavio Paz, Tiempo nublado, Barcelona: Seix Barral 1983,p. 17. Cf. Omar Astorga, La filosofía de Octavio Paz, en: Araucaria. Revista Iberoamericana De Filosofía, Política y Humanidades (Sevilla), vol. 5, No 11, enero-junio de 2004 (Octavio Paz como postmodernista avant la lettre).

6 Iring Fetscher, Das Recht, man selbst zu bleiben (El derecho de permanecer siendo uno mismo), en: Fetscher, Arbeit und Spiel. Essays zur Kulturkritik und Sozialphilosophie (Trabajo y juego. Ensayos sobre crítica cultural y filosofía social), Stuttgart: Reclam 1983, p. 152 sq.

7 Siguiendo en esto a Konrad Lorenz, Die acht Todsünden der zivilisierten Menschheit (Los ocho pecados mortales de la humanidad civilizada), Munich: Piper 1973, p. 28, 93 sq. Sobre este autor cf. Heinrich Meier, Konrad Lorenz, en: Caspar von Schrenck-Notzing (comp.), Konservative Köpfe (Cabezas conservadoras), Munich: Criticon 1978, pp. 141-156. 
nistas de diverso origen), presupone una transformación de los seres humanos en meros súbditos maleables según los requerimientos del sistema social.

Las doctrinas actuales adscritas al fundamentalismo neoliberal tienden a igualar el principio rector del mercado y la lógica de la democracia, postulando que los problemas económicos y los conflictos de la política pueden ser resueltos mediante el mismo mecanismo: la decisión de los consumidores. ${ }^{8}$ Esta concepción olvida premeditadamente que en el mercado no hay, en el fondo, un debate genuino basado en posiciones liminarmente diversas, sino la elección-según la racionalidad instrumental- de mercaderías e instrumentos adecuados a ciertos fines que no son objeto de reflexión. En cambio las decisiones democráticas, como señaló Jürgen Habermas, están inmersas -o deberían estarlo- en una discusión pública en torno a metas y paradigmas que tienen que ser valorados y fundamentados de acuerdo a argumentos racionales y a experiencias pasadas que son percibidas a través de lógicas culturales, es decir a través de factores cualitativos y no meramente cuantitativos. ${ }^{9}$

El hombre no se reduce, por consiguiente, a una racionalidad prácticopragmática, que puede ser explicada suficientemente por medio de los conflictos de intereses materiales. Como todos los seres vivientes, los humanos tienen que vivir en medio del mundo material y en confrontación con este, pero lo hacen de acuerdo a creencias, instituciones y normas que dan sentido y significación a sus esfuerzos. Como afirmó Marshall Sahlins, lo decisivo no estriba en que los modelos civilizatorios obedezcan a coerciones materiales -todas las especies animales viven así-, sino en que el hombre se doblega ante estas presiones del entorno natural siguiendo las reglas de sistemas simbólicos y normativos, que no están predeterminados exhaustivamente por el sustrato material y entre los cuales reina, por ende, una cierta variabilidad. La utilidad es algo ya interpretado culturalmente. ${ }^{10}$

\section{LA CRÍTICA CLARIVIDENTE DE MAX Weber}

El funcionamiento específico de las grandes organizaciones en los campos de la economía, la administración y la política nos hace ver los límites históricos a los que ha llegado el individuo. Como lo entrevió Max Weber de manera clarividente, la burocracia ha sido la gran triunfadora en las lides del

8 Cf. la temprana crítica a esta posición de Jürgen Habermas, Die verzögerte Moderne (La modernidad retardada) [1965], en: Habermas, Philosophisch-politische Profile (Perfiles filosóficopolíticos), Frankfurt: Suhrkamp 1998, p. 457.

9 Jürgen Habermas, Ach Europa. Kleine politische Schriften XI (Ay Europa. Escritos políticos breves), Frankfurt: Suhrkamp 2008, p. 92.

10 Cf. el interesante estudio de Marshall Sahlins, Culture and Practical Reason, Chicago / Londres: Chicago U.P. 1976, passim, en la cual Sahlins criticó el potencial explicativo de conocidas teorías de la evolución histórica centradas en el interés y la utilidad materiales, como el marxismo. 
siglo XX, con independencia del régimen político concreto. La burocratización ha diluido las distinciones entre las varias clases de trabajo, ha «parcelado el alma», la conllevado la pérdida de la libertad, ha compelido al hombre a ser un engranaje bien aceitado de una maquinaria difícil de controlar, ha creado la «jaula de hierro de la servidumbre» y ha separado la moral de la razón instrumental. La burocratización ha transformado toda forma de actuación social en algo similar al funcionamiento de una fábrica. ${ }^{11} \mathrm{Y}$ en este contexto Max Weber se planteó la «cuestión central»: ¿Qué podemos hacer para contrarrestar esta maquinaria, para preservar un «resto de humanidad» de esta parcelación del alma y de este predominio exclusivo de los principios racional-burocráticos? ${ }^{12}$ Max Weber supuso que sólo existen dos vías aceptables para mitigar la acción paralizante de la burocracia y, en general, de la racionalidad instrumental: un impulso científico-crítico y una política inteligente. A estos propósitos podrían aportar su grano de arena las individualidades bien formadas, una aristocracia cultural, ciertas fuerzas emocionales carismáticas y un pesimismo estoico y hasta heroico frente a los decursos históricos. Estos factores constituirían la única defensa contra la jaula de hierro de la servidumbre, la gran creación de la racionalidad instrumental.

A comienzos del siglo XXI tenemos una constelación general que corresponde a lo criticado por Weber acerbamente hacia el final de su vida y que hubiera merecido su rechazo enfático, pese a que él postuló y fundamentó precisamente la total abstención de juicios de valor: un pueblo sin valores éticos se vuelve servil, y una administración pública altamente burocratizada produce indefectiblemente políticos corruptos y oportunistas. ${ }^{13}$ No es superfluo recordar que Max Weber, adversario de toda ciencia que incluyera la dimensión normativa y ética, los enunciados valorativos y las tomas de posición política,,${ }^{14}$ sintiera pa-

11 Max Weber, Gesammelte Aufsätze zur Religionssoziologie (Ensayos reunidos sobre sociología de la religión), Tübingen: Mohr-Siebeck 1920/1921, t. I, p. 204, 521, 552, 569; t. III, p. 120; Weber, Gesammelte politische Schriften (Escritos políticos reunidos; compilación de Johannes Winckelmann), Tübingen: Mohr-Siebeck 1980, pp. 308, 330-332, 556-558.

12 Max Weber, Gesammelte Aufsätze zur Soziologie und Sozialpolitik (Trabajos reunidos sobre sociología y política social), Tübingen: Mohr-Siebeck 1924, p. 414.

13 Testimonios de esta crítica weberiana altamente emotiva, basada en la necesidad de solidaridad y fraternidad, en el excelente trabajo de Arthur Mitzman, La jaula de hierro. Una interpretación histórica de Max Weber [1969], Madrid: Alianza 1976, pp. 161-163.

14 Max Weber,Die «Objektivität» sozialwissenschaftlicher Erkenntnis (La «objetividad» del conocimiento en ciencias sociales) [1904], en: Max Weber, Soziologie, weltgeschichtliche Analysen, Politik (Sociología, análisis histórico-universales, política), [compilación de Johannes Winckelmann], Stuttgart: Kröner 1968, pp. 188-190; Weber, Der Sinn der «Wertfreiheit» der Sozialwissenschaften (El sentido de la «abstención de valores» en la ciencia social) [1917], en: ibid., p. 265.- Sobre esta temática cf. el importante texto de Volker Heins, Max Weber zur Einführung (Introducción a Max Weber), Hamburgo: SOAK / Junius 1990, p. 24 sqq., 37, 56 sq. 
radójicamente una gran nostalgia por valores y normas solidarias y humanistas: lamentó que la racionalización de la vida social y la burocratización del ámbito político-institucional hubiesen relegado los valores normativos y las actitudes emotivas (como la fraternidad, la gracia y la dignidad personales, la creatividad original) casi exclusivamente hacia el campo de la intimidad, la mística religiosa y las artes, y los hubieran desplazado de la esfera público-política. La suya fue una añoranza de elementos premodernos, como la fraternidad, la religiosidad, la espontaneidad y la búsqueda de sentido. ${ }^{15}$

\section{LA CONTINUADA NECESIDAD DE UNA POSICIÓN CRÍTICA}

Hoy en día es menester una actitud eminentemente crítica que ponga en cuestionamiento esta magna alianza de la tecnología avanzada con el infantilismo producido por la organización socio-política, alianza que subyace a la ilusión generalizada de que la técnica puede resolver todos los problemas de la humanidad. Esta quimera contemporánea es alimentada por la perfidia de los políticos, la ingenuidad de los intelectuales y el pragmatismo de las élites (incluida entre estas la cleptocracia de los países postcomunistas). Esta ficción ha sido compartida hasta el final por los intelectuales marxistas más lúcidos. ${ }^{16}$

En cambio el espíritu crítico que nos hace falta como en cualquier otra época es el de la filosofía auténtica: un sentimiento de nostalgia, desencanto y hasta repugnancia con respecto a las incongruencias y aberraciones de que está lleno el mundo actual. Nostalgia ${ }^{17}$ porque el hombre nunca ha vivido por largo tiempo en un verdadero hogar, desencanto porque las realizaciones de la praxis no están jamás a la altura de nuestros sueños. No hay duda, por otra parte, de que la experiencia de la incertidumbre, los temores y todas las formas de alienación han tenido también su aspecto positivo al ensanchar nuestro conocimiento del mundo, al enriquecer nuestras perspectivas y al hacernos comprender lo valioso en aquello que desaprobamos. El espíritu crítico nos enseña a discernir: no cualquier vivencia o doctrina es aceptable por el hecho de ser nueva o extraña: hasta lo históricamente necesario no constituye de ninguna manera lo ética-

15 Max Weber, Vom inneren Beruf zur Wissenschaft (Sobre la profesión de la ciencia) [1919], en: Weber, Soziologie ..., op. cit. (nota 14), p. 338. Cf. Arthur Mitzman, op. cit. (nota 13), p. 163, 170, 179, 203, 256, 263, 271.

16 Cf. el canto celebratorio de los milagros de la tecnología en una obra del periodo inicial del régimen comunista, obra que tuvo una inmensa difusión en los primeros años de la Unión Soviética: Nikolaj Buxarin / Evgenij Preobrazhenskij, ABC du communisme [1919], París: Maspero 1971 ( 2 vols.).

17 La idea de que la filosofía es, en realidad, nostalgia, fue expresada por Georg Lukács siguiendo a Novalis y antes de su conversión al marxismo. G. Lukács, Geschlossene Kulturen (Culturas cerradas) [1914/1915], en: Lukács, Schriften zur Literatursoziologie (Escritos sobre sociología de la literatura), Neuwied / Berlin: Luchterhand 1968, p. 81. 
mente admisible o lo estéticamente recomendable. Y la reflexión más ardua o más refinada no debe paralizar nuestra capacidad de emitir juicios valorativos que pueden aplicarse a la praxis cotidiana. Además: el obtener conocimientos probables en el amplio campo social no nos da derecho a creer que poseemos un saber enteramente cierto e indubitable en los terrenos político-históricos. Pero: comprender no es perdonar.

Jürgen Habermas expuso la tesis de que hoy en día la filosofía sólo puede subsistir en cuanto crítica, es decir como análisis del fundamento de toda creencia -incluida la pretensión de totalidad de toda religión y de todo conocimiento metafísico-, es decir como elemento reflexivo de toda actividad humana y en cuanto cuestionamiento de toda interpretación afirmativa del mundo y de la sociedad. ${ }^{18}$ Como «resistencia consciente contra los lugares comunes» $\mathrm{y}$ «obligación de no ceder ante la ingenuidad $»^{19}$ (Theodor W. Adorno), el impulso crítico-filosófico puede aun brindar eminentes servicios a la humanidad, puesto que representa un estímulo contrario a la resignación generalizada y a las certezas convencionales de la época, por un lado, y la nostalgia de una vida bien lograda, por otro. Este impulso está opuesto a la actitud predominante hoy en día en los campos académicos e intelectuales, donde lo habitual es plegarse a la moda del momento con genuina devoción; como en muchas otras épocas, lo necio, lo desaconsejado y lo irrisorio es estar fuera de la ortodoxia de turno. John Stuart Mill, el gran pensador liberal del siglo XIX, dijo que lo peligroso de su tiempo era la suave tiranía de la opinión pública, sin que existiese un régimen despótico consagrado a prohibiciones y exclusiones. Que tan pocos se atrevieran a ser excéntricos y tener coraje revelaría el principal peligro de la era liberal-democrática. ${ }^{20}$

En este contexto es donde mantienen su relevancia fenómenos como la religión, las jerarquías no técnico-económicas y la esfera de la estética (basada en el concepto clásico de belleza), fenómenos que la modernidad y, más aun, sus últimos apéndices postmodernistas, tratan de disipar. A riesgo de ser confundido con un crítico conservador de la cultura, hay que aseverar que la decadencia de la dimensión simbólica ha conllevado un empobrecimiento inocultable de la civilización actual. La ruina de las convenciones en el trato social, la abolición de ritos y ceremonias, la dilución del tacto y la cortesía, la transformación del arte

18 Jürgen Habermas, Wozu noch Philosophie (Porqué aun filosofía?) [1971], en: J. Habermas, Philosophisch-politische..., op. cit. (nota 8), p. 31.

19 Theodor W. Adorno, Philosophische Terminologie. Zur Einleitung (Terminología filosófica. Introducción), Frankfurt: Suhrkamp 1973, t. I, p. 132; Adorno, Wozu noch Philosophie (Para qué aun filosofía), en: Adorno, Eingriffe. Neun kritische Modelle (Intervenciones. Nueve modelos críticos), Frankfurt: Suhrkamp 1964,p. 21.

20 John Stuart Mill, Über die Freiheit (Sobre la libertad) [1859], Stuttgart: Reclam 1974, p. 93. 
en una técnica de publicidad y la declinación de la estética y el ornato públicos han conducido a estabilizar un mundo regido exclusivamente por principios técnicos, dominado por la uniformidad cultural y caracterizado por la pobreza emotiva, la difusión de un narcisismo tan cínico como obvio y la pérdida del sentido de responsabilidad.

Hoy en día las personas se saben intercambiables entre sí: al no recibir el reconocimiento ${ }^{21}$ de los otros, despliegan una baja auto-estima, muy proclive a la destrucción del entorno y a la automutilación. En su espléndido tratado sobre los orígenes el totalitarismo Hannah Arendt señaló acertadamente que el desamparo existencial del Homo faber, el autodesprecio y la sensación de la escasa valía de cada persona se hallan en la base de ese terrible régimen, que fue fortalecido por el aislamiento y la atomización de los individuos, por el debilitamiento de los vínculos de parentesco en favor de la lealtad omnívora que exigen las organizaciones anónimas, por la disolución (muchas veces anhelada) del individuo en movimientos y modelos colectivistas, por el decaimiento de las normas éticas convencionales (bajo el pretexto de un realismo amoral) y por el sentimiento de impotencia ante dilatadas burocracias estatales. ${ }^{22}$ Hasta en sociedades bien administradas, como en la Suecia socialdemocrática de las últimas décadas, se advierten el hastío de la vida despersonalizada, la mezquindad burocrática y el centralismo asfixiante causados por la tutela omnipotente del Estado benefactor y la ruina de la esfera simbólico-cultural. ${ }^{23}$

\section{LA CRÍTICA A LOS EXCESOS DE LA MODERNIDAD}

La modernidad y el orden burgués-capitalista han significado, sin duda alguna, el triunfo del individualismo y del racionalismo, pero, al mismo tiempo, han minado desde adentro al individuo y a la razón. Cuanto más racional funciona la sociedad, cuanto más justicia social brinda a sus miembros, tanto más reemplazable resulta cada individuo y tanto menos es este mismo diferenciable de sus congéneres. La lógica de la evolución histórica conlleva la disolución de las

21 Acerca de una teoría del reconocimiento cf. las obras fundamentales de Axel Honneth, Die zerrissene Welt des Sozialen. Sozialphilosophische Ansätze (El mundo desgarrado de lo social. Enfoques de filosofía social), Frankfurt: Suhrkamp 1999 (edición ampliada); Axel Honneth, $P a-$ thologien der Vernunft. Geschichte und Gegenwart der Kritischen Theorie (Patologías de la razón. Historia y presente de la Teoría Crítica), Frankfurt: Suhrkamp 2007.

22 Hannah Arendt, The Origins of Totalitarianism [1951], New York / Londres: Harcourt Brace 1973, p. 323, 330, 475, 477.- Cf. también Jürgen Habermas, Hannah Arendts Begriff der Macht (El concepto de poder en Hannah Arendt), en: Habermas, Politik, Kunst, Religion. Essays über zeitgenössische Philosophen (Política, arte, religión. Ensayos sobre filósofos contemporáneos), Stuttgart: Reclam 1978, p. 110.

23 Hans Magnus Enzensberger, Ach Europa! (Ah Europa), Frankfurt: Suhrkamp 1987, pp. $9-49$. 
odiosas formas exteriores de las jerarquías y diferencias sociales, pero también significa la nivelización de los individuos por obra de los grandes colectivos y las necesidades tecnológicas del presente. ${ }^{24} \mathrm{El}$ florecimiento de la tecnología, en cuanto la manifestación más patente de la razón instrumental, y la exacerbación del narcisismo asocial, como la culminación del neoliberalismo, amenazan con hacer superfluos el legado humanista, el espíritu crítico y la consciencia personal. El endiosamiento de la evolución técnica ha conducido a que la máquina pueda prescindir del maquinista. El perfeccionamiento de los instrumentos técnicos hace superflua la reflexión en torno a las metas para las cuales aquellos fueron creados. Como afirmó Max Horkheimer, los medios desplazan a los fines. ${ }^{25}$ Comportamientos basados en la solidaridad y la espontaneidad, la capacidad de reflexión crítica y los elementos lúdicos asociados a la fantasía creativa han sido reemplazados paulatinamente por otras destrezas que gobiernan el mundo actual. Las pericias técnicas, la capacidad de adaptación al entorno, la mimetización con la mayoría de turno y la astucia en las cosas pequeñas de la vida constituyen las virtudes indispensables de nuestra era. «Hoy se ha hecho realidad el sueño de que las máquinas desplieguen habilidades humanas, pero los hombres actúan cada vez más como si fuesen máquinas». ${ }^{26}$

El mundo contemporáneo, basado en los logros de la ciencia y la técnica, no resulta, entonces, tan positivo y promisorio como lo creen sus apologistas. La modernidad ha engendrado formas contemporáneas y menos visibles de prejuicios, discriminación y dogmatismo, que, debido a su envoltorio técnico y módico, no pueden ser constatadas fácilmente. Por otra parte, el designio de crecer y desarrollarse sin restricciones en un mundo finito no deja de exhibir aspectos irracionales. Ya en 1966, en su crítica del progeama «The Great Society» del entonces presidente norteamericano Lyndon Johnson, Herbert Marcuse señaló que la dinámica representada por una economía que crece sin fin y por una productividad que se incrementa sin límites es esencialmente irracional, pues los factores de esta dinámica se transforman en objetivos en sí mismos, en metas normativas autónomas, desligadas de necesidades y dimensiones humanas. Una sociedad de despliegue económico inexorable e imparable es un sistema de inmenso derroche y pésima asignación de recursos y no podría constituir un «puerto seguro», un «lugar de paz», donde el hombre se encuentre consigo mismo, liberado de los incesantes imperativos de las maquinarias productiva y administrativa, imperativos que van siempre ligados a procesos de manipula-

24 Max Horkheimer, Pessimismus heute (Pesimismo hoy), in: Horkheimer, Sozialphilosophische Studien (Estudios social-filosóficos), Frankfurt: Athenäum-Fischer 1972, p. 142.

25 Max Horkheimer,Zur Kritik der instrumentellen Vernunft (Crítica de la razón instrumental), Frankfurt: Fischer 1967, p. 124, 144.

26 Max Horkheimer, Gesellschaft im Übergang, op. cit. (nota 2), p. 101. 
ción masiva. Además: un modelo económico de crecimiento infinito perpetúa paradójicamente la escasez, puesto que hace brotar incesantemente nuevas necesidades artificiales de bienes y servicios; se vuelve perenne la lucha de los individuos por sobrevivir en medio de una competencia despiadada y para tratar -infructuosamente- de elevar permanentemente el propio nivel de consumo. ${ }^{27}$ Entre las consecuencias paradójicas del mundo actual se hallan el activismo por el activismo, el apetito permanente por nuevas experiencias, la superación de toda frontera y de todo tabú (que siempre crecen y se reproducen), y todo esto en medio de la nostalgia del ser humano por algo permanente, estable y confiable. No encuentra el hombre satisfacción ni en la esfera estética, ni en las creencias religiosas y ni siquiera en las prácticas políticas progresistas que están de moda. Todo esto nos sucede porque olvidamos los límites de un mundo finito.

La actualidad de muchos filósofos y cientistas sociales, como Karl Marx, no reside en sus análisis concretos y en sus conclusiones práctico-políticas -de índole relativa y discutible-, sino en su impulso ético y en su crítica radical de los comportamientos y las instituciones que impiden el desarrollo libre de cada individuo y, por ende, de la sociedad en su conjunto. En estos textos magnos se puede detectar el propósito de evitar la idolatría de la historia, la exaltación del éxito material y la sumisión bajo los poderes establecidos. Al mismo tiempo se advierte en ellos el intento de no resignarse ante los hechos consumados y (aun en el caso de Max Weber) emitir juicios valorativos acerca de la evolución socio-política.

Por razones de equidad, hay que mencionar también los aspectos negativos del orden premoderno. Como la crítica racionalista se ha consagrado a ello de manera exhaustiva desde el siglo XVIII, podemos resumirla en pocas palabras. La tradicionalidad ha sido el mundo del colectivismo y el conformismo, en el cual la variabilidad de roles era muy restringida; el hombre estaba habitualmente condenado a asumir una sola función durante toda su vida, que era simultáneamente su identidad. Las estructuras político-institucionales premodernas eran débiles, improductivas e inconfiables; su capacidad de actuación era tan limitada como era fragmentaria su penetración geográfica y espacial. Los sistemas premodernos se destacaban por ser estáticos y altamente jerárquicos, en los cuales la autonomía del individuo estaba, como se sabe, sometida a los avatares más diversos, como los caprichos del gobernante de turno y la tuición asfixiante de las confesiones religiosas. ${ }^{28}$

27 Herbert Marcuse, Das Individuum in der «Great Society» (El individuo en la «Great Society») [1966], en: Marcuse, Ideen zu einer kritischen Theorie der Gesellschaft (Ideas sobre una teoría crítica de la sociedad), Frankfurt: Suhrkamp 1969, p. 158 sq.

28 Entre la enorme literatura existente sobre esta temática cf. el compendio de Patricia Crone, Pre-Industrial Societies, Oxford: Blackwell 1989. 
Pero, como ya se mencionó, son los aspectos negativos de la modernidad los que nos hacen volver la vista a la tradicionalidad. Las ciencias sociales y la etnografía han subrayado la enorme relevancia social de valores y modelos normativos pre-industriales y preburgueses, como la heterogeneidad estructural, la familia extendida y las redes de parentesco, los sistemas de solidaridad y reciprocidad inmediatas, la estabilidad emotiva brindada por lazos primarios sólidos -que luego resultan tan indispensables para producir individualidades bien conformadas-, el tener tiempo para entregarse a la imaginación y espacio para el ocio y también la existencia de jerarquías sociales transparentes y más o menos razonables. La revalorización de estos factores por las ciencias sociales y la literatura nos exime de examinarlos en este ensayo. Por otra parte: muchas de las normativas y las pautas de comportamiento tradicionales, y precisamente algunas de las más difundidas, no merecen francamente ser rescatadas.

El propósito de reivindicar la tradicionalidad adquiere el carácter de un acto de justicia histórica. Después de la Revolución Francesa emergió una ola de refutaciones de la Ilustración, la Enciclopedia y de todo lo que parecía estar vinculado a ellas; estas críticas -sobre todo las asociadas al romanticismocontenían muchas veces observaciones muy agudas sobre los excesos del racionalismo, impugnaciones clarividentes del capitalismo y fragmentos valiosos en torno a una vida bien lograda. Pero muchos de estos esfuerzos restaurativos terminaron a menudo en una celebración más o menos burda de lo irracional y lo autoritario, en la irrupción grosera del patriotismo y el nacionalismo, en el cultivo premeditado de los prejuicios convencionales y en el uso profano de la religiosidad santurrona. Las terribles consecuencias de todo esto pueden ser rastreadas hasta los peores sistemas totalitarios del siglo $\mathrm{XX} .{ }^{29}$ Estos aspectos del orden premoderno merecen quedar en el más profundo olvido.

El cuestionamiento de una época de la superficialidad generalizada, de la vida rápida $\mathrm{y}$, por ende, ligera en muchos sentidos, y del amor desmedido por cualquier novedad trivial representa evidentemente un lugar común de la crítica cultural conservadora, pero ese cuestionamiento va más allá de una posición que defiende el pasado por el pasado mismo. A comienzos del siglo XXI hemos llegado a un endiosamiento tal de la técnica que el hombre en cuanto mero ser viviente se avergüienza ante la perfección alcanzada por sus productos: las últimas maravillas de la industria y la informática parecen superar las destrezas tan deficientes del ciudadano común y corriente. Este embeleso ante las obras de su propia creación conduce paradójicamente a que el hombre pierda el sentido de proporción con respecto a sus propios inventos: ya no se puede

29 Sobre esta temática cf. el interesante tratado de Herbert Marcuse, Studien über Autorität und Familie (Estudios sobre autoridad y familia), en: H. Marcuse, Ideen..., op. cit. (nota 27), pp. 113-129. 
imaginar las consecuencias negativas que están asociadas a su poder creador. El hombre tiende, por lo menos, a convertirse en un servidor de la técnica, la cual transciende así su clásico rol de instrumento neutral.

\section{UNA SÍNTESIS RAZONABLE ENTRE LO TRADICIONAL Y LO MODERNO}

No podemos retornar al mundo pre-industrial, pero sí podemos intentar una simbiosis entre los elementos positivos de lo premoderno y de la modernidad: podemos, por ejemplo, tratar de no destruir ni desvirtuar nuestras tradiciones razonables, y combinarlas con lo rescatable de la modernidad. Estos esfuerzos sincretistas no son ni tan raros ni condenados a priori al fracaso: en gran parte la historia universal está construida por ellos. Y la evolución del pensamiento tiene lugar mediante miradas retrospectivas, por medio de un retorno a temáticas y motivos que parecían indefectiblemente superados, pues ningún problema posee -por suerte- una solución definitiva, y bajo ciertas circunstancias los temas más abstrusos y curiosos nos pueden brindar inspiración y ganancias cognoscitivas.

En la actual sociedad compleja y sobredesarrollada la solidaridad humana sólo se puede dar como la consciencia de un desamparo existencial que atañe a todos. Lo que puede unir a los hombres es la sensación de soledad colectiva, el percatarse de la precariedad de la vida a largo plazo en un mundo finito y amenazado por la propia evolución humana y el reconocer la serie interminable de horrores e injusticias que jalonan la historia. Y esta percepción de abandono liminar sólo puede ser compensada por la creencia en lo transcendente y por la preservación de modelos de convivencia que conservan los cimientos de una sociedad genuinamente humana. La angustia hace que los mortales se cierren con respecto a sus congéneres, pero el mismo impulso homogeneizador de la civilización moderna destruye las distancias entre ellos. Al diluirse su individualidad los hombres pierden la facultad de comunicarse entre ellos y, por ende, la iniciativa socio-política, que es la posibilidad de enlazar libre y espontáneamente los intereses divergentes para una acción común. El Estado y las fuerzas prevalecientes pueden así disponer sobre una masa amorfa de «ciudadanos» y manipularlos arbitrariamente. El triunfo de la racionalidad instrumental aniquila paulatinamente el diálogo entre iguales e imposibilita a largo plazo la resolución pacífica de conflictos, la que depende en última instancia de la habilidad expresiva de los hombres, de su idoneidad para ensayar alternativas socio-políticas y organizativas y de sus aptitudes para reinterpretar la tradición. El discernimiento crítico, la facultad para comprender valores éticos y estéticos, el derecho a la expresión espontánea de los anhelos y el recuerdo esclarecedor de los sufrimientos pasados representan sin duda algunos elementos clásicos de la evolución humana, es decir: son también parte de la era premoderna. Ellos se revelan hoy como indispensables para amortiguar la civilización conformada 
por el principio de rendimiento, la burocratización y nivelización de la vida cotidiana, las neurosis colectivas y la destrucción del medio ambiente.

La síntesis postulada entre lo tradicional y lo moderno puede ser explicitada brevemente mencionando el rol que la religiosidad (y aspectos afines) puede aun jugar en el mundo moderno. Las diferencias entre religión y mitos, por un lado, y saberes objetivos y conocimientos derivados de experimentos científicos, por otro, son importantes. Sobre esta diferencia se basa una buena parte de la civilización occidental moderna. Sería una absoluta necedad negar esta distinción palpable y simplemente fundamental. Pero hay también semejanzas entre ambas formas del quehacer humano, similitudes que ahora comienzan a ser reconocidas en cuanto tales y que impiden la desvalorización y el desprecio sistemáticos del mito, la religión y, en general, de los valores y las instituciones premodernas. Las ciencias naturales parecen gozar de injustificados privilegios respecto de las sociales y espirituales, privilegios que se derivan de una curiosa convicción en la mayor objetividad y exactitud de las primeras. Las ciencias naturales han resultado ser, empero, tan tributarias como las otras del entorno personal, cultural e histórico de los científicos, y sus practicantes tan proclives a prejuicios e influencias de todo tipo, incluidas las políticas, como aquellos que investigan leyendas y costumbres de otros pueblos. Insistiendo en esta posibilidad, Émile Durkheim llegó a la conclusión de que el proceso de constitución de las ciencias no difiere substancialmente del de las religiones. ${ }^{30}$ Las creencias religiosas parecen representar una vivencia muy extendida y no reducible a otro tipo de experiencia; parecen conforman la base conceptual de las actividades humanas ulteriores. El hombre vive vinculado inextricablemente a saberes previos, sobre los cuales se edifica la ciencia contemporánea, saberes que son comunes a la razón y a la religión. La ciencia no está casi nunca libre de presupuestos y selecciones de valores que ocurren en la esfera precientífica. La ciencia se construye sobre un humus cultural de cierto espesor; las teorías contemporáneas sobre el universo parten también de la presuposición de un orden cósmico aceptado en cuanto científico porque una mayoría aleatoria de científicos y teorías reputadas como tales lo consideran así. Si esto es así, tenemos que retornar a una humildad liminar: los conceptos de hombre y humilde provienen probablemente del mismo humus de la tierra. ${ }^{31}$

En un pasaje poco conocido Herbert Marcuse aseveró que «la idea de la razón no es necesariamente antirreligiosa. La razón deja la posibilidad abierta de que el mundo sea una creación de Dios y que su ordenamiento sea divino

30 Cf. Emile Durkheim, Les formes élémentaires de la vie religieuse, Paris 1912, passim.

31 Sobre este concepto de reminiscencia kantiana cf. Jesús Avelino de la Pienda, Filosofía de las creencias, en: Revista de Filosofia De La Universidad De Costa Rica (San José), vol. XXXVII, $\mathrm{N}^{\circ}$ 92, junio-diciembre de 1999, p. 239. 
y determinado por este fin». ${ }^{32}$ Las actuales inclinaciones a deconstruir y desmistificar todo fenómeno relacionado con lo religioso y lo mítico conllevan a menudo la imposición del propio criterio del investigador, para quien la grandeza y la lógica interna de los asuntos estudiados no son fácilmente comprensibles. ${ }^{33}$ Los mitos y las doctrinas religiosas tienen la función de recordar a los hombres su índole pasajera y lo efímero de todos sus actos. La religión puede ayudar al hombre a que este evite el acto máximo de soberbia y desmesura (hybris), que es colocarse en lugar de Dios en la esfera de lo absoluto. Las versiones más plausibles de la teología abandonan la pretensión de conocer inequívocamente a Dios y, por lo tanto, a penetrar la esencia de todo el universo, reconociendo así los límites de nuestras facultades cognoscitivas, pero postulando la idea de que si bien no podemos comprender exhaustivamente el mundo, sí podemos amarlo y conservarlo.

Un mínimo de creencias religiosas ha resultado ser uno de los antídotos más eficaces contra la arrogancia del hombre contemporáneo y sus consecuencias práctico-políticas. La concepción de responsabilidad por el futuro y sus generaciones no puede sustentarse sin una base ético-religiosa que englobe la idea de pecado, la noción de falta individual por transgredir los mandamientos de Dios. La carencia de una consciencia de culpabilidad y de un sentimiento de error y delito personales constituye, como se sabe, una de las características recurrentes y decisivas de los políticos de todas las latitudes; distinguidos intelectuales (como Martin Heidegger), involucrados en los regímenes totalitarios más terribles, han demostrado también que el sentimiento de culpabilidad personal es un bien terriblemente escaso. Pero sólo la consciencia de la culpa y responsabilidad individuales puede llevar al remordimiento sincero y, por ende, a una actitud que modifique realmente las pautas de comportamiento que causaron tanto daño a lo largo de la historia universal. (La inmensa mayoría de los intelectuales, preocupados por plegarse a las corrientes de moda del momento y por no separarse de la tendencia predominante -ayer marxistas, hoy postmodernistas-, no ha contribuido al surgimiento de un sentimiento de responsabilidad de relevancia histórica y social).

En este contexto es conveniente recordar que Immanuel Kant comenzó su obra principal señalando que la razón es asediada por preguntas que ella no puede rechazar pues provienen de la naturaleza misma de la razón, pero que superan toda la capacidad de la razón humana. ${ }^{34}$ Estas cuestiones son de índole

32 Herbert Marcuse, Vernunft und Revolution. Hegel und die Entstehung der Gesellschaftstheorie (Razón y revolución. Hegel y el origen de la teoría social), Neuwied / Berlin: Luchterhand 1962, p. 225.

33 Cf. Mircea Eliade, Le sacré et le profane, París: Gallimard 1965, p. 9.

34 Immanuel Kant, Kritik der reinen Vernunft (Crítica de la razón pura) [prólogo de 1781, no incluido en la edición posterior de 1787], en: Kant, Werke in zehn Bänden (Obras en diez tomos), 
estrictamente metafísica: la existencia de Dios, el inicio del universo, la esencia de la libertad, el sentido del mundo y la inmortalidad del alma. ${ }^{35}$ Son indemostrables para la razón pura, pero, según Kant, son los postulados fundamentales de la razón práctica. La misma facultad que impide el análisis y la aclaración de las cuestiones metafísicas mediante la razón pura obliga a ponerlas sobre el tapete de una discusión más amplia; este hecho nos muestra las limitaciones propias de la razón. ${ }^{36}$ Cuando la reflexión se percata de límites, entonces ya está dado el primer paso para sobrepasarlos. Aunque no se pueda aplicar la reflexión analítica al territorio allende esa frontera, la consciencia ya se da cuenta de la existencia de esa otra dimensión. El campo de la razón práctica -por ejemplo la conciencia moral- está alejado y contrapuesto al terreno de los instintos, es decir de las llamadas necesidades «naturales». El ejercicio de la libertad ética es también el intento de romper las cadenas de la causalidad que nos atan a los imperativos de la naturaleza y de la autoconservación de la especie. La libertad puede ser concebida como el triunfo (momentáneo) de la condición humana sobre el aparato de los impulsos primarios, como el depasar la dimensión de la pura necesidad de la supervivencia. Actuamos libremente cuando superamos la voluntad instintiva -vinculada a la razón instrumental- y nos movemos en la esfera del deber libremente aceptado. Esta conciencia kantiana es autónoma en el sentido de no representar una causa inexorable, sino es la razón elegida sin constricciones para una acción posterior. La conciencia moral nos prescribe una actuación diferente de las coerciones obligatorias del mundo natural. La naturaleza en nosotros quiere conservarse y expandirse: los hombres y los recursos son considerados entonces sólo como instrumentos para este objetivo. La ética exige otra cosa: que el prójimo no sea degradado a la categoría de medio para la consecución de nuestras metas, sino pensado siempre como un fin en sí mismo. La libertad del otro constituye una parte importante de mi actuación moral. Y por ello esta concepción de una ética humanista no puede renunciar a una dimensión más allá de los cálculos racionalistas e instrumentalistas, dimensión que es precisamente el campo de la metafísica, cuya fundamentación es el amor de Dios.

\section{CODA ABIERTA}

El genuino saber es impensable sin un motivo que hoy, en la era del predominio total del principio de rendimiento y eficacia, puede ser calificado de

compilación de Wilhelm Weischedel, Darmstadt: WBG 1968, t. 3, p. 11.

35 Immanuel Kant, Kritik der reinen Vernunft, [prólogo a la segunda edición de 1787], en: Kant, Werke..., ibid., t. 3, p. 33 sq.

36 Immanuel Kant, Kritik der praktischen Vernunft (Crítica de la razón práctica) [1788], en: Kant, Werke..., ibid., t. 6, pp. 252-266. 
platónico y, obviamente, de premoderno: el entusiasmo. Como aseveró Adorno, se añora aquello que no es y no puede ser una posesión segura: la auténtica sabiduría ama lo que no puede ser utilizado estratégica o instrumentalmente, y cuyo modelo último -metafísico en el sentido original- es el amor de Dios. ${ }^{37}$

No hay que apoyar, obviamente, la módica confusión entre opinar, saber y creer, como si todos estos factores tuviesen el mismo peso y la misma validez. La investigación comparada en sociología, lingüística, etnografía y estudios religiosos ha conmovido la antigua certidumbre de que la religión se ocupaba de cuestiones meramente especulativas y la ciencia de fenómenos estrictamente verificables. Como ya afirmó Georg Wilhelm Friedrich Hegel en sus primeros escritos fragmentarios, la contraposición que se manifiesta a menudo entre la razón y el acto de creer puede ser considerada como una oposición aparente, puesto que ambas esferas se mueven dentro del mismo elemento y están influidas por un mismo designio humano, que es el de percibir lo absoluto. Su oposición es fructífera, y es conveniente que ambas no se diluyan, sino que se mantengan diferenciables en sus modos de proceder. ${ }^{38}$ El peligro actual consiste en que a la filosofía contemporánea y al pensamiento postmodernista les es indiferente esta compleja, pero diferenciada relación entre saber y creer, entre la comprensión del mundo de los fenómenos relativos y el vislumbrar lo absoluto. Hoy en día se da preferencia a una amalgama mal aderezada de todo un poco, para la cual no existen distinciones -y, por lo tanto, vínculos discernibles- entre la mera opinión (doxa), el saber genuino (episteme) y el credo auténtico (pistis). Por ello se ha disuelto asimismo la base de toda moralidad auténtica, que no se puede demostrar empíricamente, pero que ha constituido siempre la base para nuestra razón práctica, es decir para aquella que rige las interacciones con nuestros semejantes. ${ }^{39}$

Hoy en día es imprescindible un cuestionamiento radical del mito moderno (y postmoderno) por excelencia: la razón predominante es, por un lado, la

37 Theodor W. Adorno, Philosophische Terminologie, op. cit. (nota 19), t. I, pp. 80-84, 118 sq., 131 sq., 171,210 sq.

38 Georg Wilhelm Friedrich Hegel, Fragmente über Volksreligion und Christentum (Fragmentos sobre la religiosidad popular y el cristianismo) [1793/1794], en: Hegel, Werke in 20 Bänden (Obras en 20 tomos), compilación de Eva Moldenhauer y Karl Markus Michel, Frankfurt: Suhrkamp 1971, t. I: Frühe Schriften (Escritos tempranos), pp. 11, 15 sq., 89 sqq. 101-103; Hegel, Entwürfe über Religion und Liebe (Esbozos sobre religión y amor) [1797/1798], en: ibid., pp. 250-254. Cf. también Hegel, Phänomenologie des Geistes (Fenomenología del espíritu), en: Hegel, Werke..., ibid., t. III, pp. 495-498, 502, 558.

39 Cf. Karl Löwith, Wissen..., op. cit. (nota 4), pp.5-9 (sobre la compleja relación entre estos factores en la filosofía de Immanuel Kant y cómo esta vinculación fue concebida de otra manera por G. W. F. Hegel).- Cf. también Immanuel Kant, Kritik der reinen Vernunft, segunda parte, op. cit. (nota 34), t. 4, pp. 687-695. 
técnico-instrumental y, por otro, aquella de la conformidad con lo que existe en un momento dado. La filosofía y el impulso crítico, esas ocupaciones de origen premoderno, no nos pueden brindar con seguridad respuestas correctas a todas nuestras preguntas, pero, al inducirnos a la reflexión, nos abren posibilidades de conocimiento y asombro, de las cuales no nos habíamos percatado a causa de nuestros hábitos. Al ensanchar nuestras perspectivas, la filosofía y el impulso crítico relativizan la arrogante certidumbre de la racionalidad instrumental hoy prevaleciente, nos liberan de falsas firmezas y de la tiranía de lo acostumbrado, y nos conducen así a nuevas formas de nuestra propia dignidad. Hay que desconfiar de la razón: sus obras a lo largo de los dos últimos siglos han sido parcialmente monstruosas. Pero según sus propias reglas ella permite que se la ponga en cuestionamiento, y esto constituye uno de los mayores avances de la humanidad. Sigmund Freud exhibió bastante escepticismo con respecto al potencial explicativo de la razón, pero una desconfianza aun mayor frente a todos los otros métodos que tratan de explicar el acontecer humano. Todo fenómeno de tradicionalidad debe ser sometido al filtro de la razón. La tradición rescatable se revela como la herencia razonable: se halla al final y no al comienzo de nuestros esfuerzos interpretativos y presupone el tamizado del espíritu crítico. ${ }^{40}$

Hugo C. F. MansiLla estudió ciencias políticas y filosofía en universidades alemanas. Hizo su Magister rerum politicarum en 1968 y su doctorado en 1973 (ambos magna cum laude). La Universidad Libre de Berlin le confirió la venia legendi en 1976. Ha sido profesor visitante en universidades de Alemania, Australia, España y Suiza. En España fue catedrático visitante del Instituto de Altos Estudios José Ortega y Gasset de la Universidad Complutense. Desde 1999 es regularmente catedrático visitante de la Universidad de Zurich (Suiza). Es miembro de número de la Academia de Ciencias de Bolivia y correspondiente de la Real Academia Española. Ha publicado varios libros sobre sociología política, crítica de mentalidades autoritarias y ecología política.

Dirección electrónica: hcf_mansilla@yahoo.com

40 Cf. Zygmunt Bauman, Moderne und Ambivalenz. Das Ende der Eindeutigkeit (Modernidad y ambivalencia. El fin de la univocidad) [1991], Frankfurt: Fischer 1996, p. 305 (siguiendo un argumento de Octavio Paz). 
